\title{
Article
}

\section{Multiscale Exploration and Experimental Insights into Separating Neutral Heterocyclic Nitrogen Compounds using [emim][NO3] as an Extractant}

\author{
Lianzheng Zhang, Xiaobin Bing, Ziqi Cui, Juan A. Labarta, \\ Dongmei Xu, Jun Gao, Shixue Zhou, and Yinglong Wang \\ ACS Sustainable Chem. Eng., Just Accepted Manuscript • DOI: 10.1021/ \\ acssuschemeng.0c00304 Publication Date (Web): 23 Mar 2020
}

Downloaded from pubs.acs.org on March 23, 2020

\section{Just Accepted}

"Just Accepted" manuscripts have been peer-reviewed and accepted for publication. They are posted online prior to technical editing, formatting for publication and author proofing. The American Chemical Society provides "Just Accepted" as a service to the research community to expedite the dissemination of scientific material as soon as possible after acceptance. "Just Accepted" manuscripts appear in full in PDF format accompanied by an HTML abstract. "Just Accepted" manuscripts have been fully peer reviewed, but should not be considered the official version of record. They are citable by the Digital Object Identifier (DOI®). "Just Accepted" is an optional service offered to authors. Therefore, the "Just Accepted" Web site may not include all articles that will be published in the journal. After a manuscript is technically edited and formatted, it will be removed from the "Just Accepted" Web site and published as an ASAP article. Note that technical editing may introduce minor changes to the manuscript text and/or graphics which could affect content, and all legal disclaimers and ethical guidelines that apply to the journal pertain. ACS cannot be held responsible for errors or consequences arising from the use of information contained in these "Just Accepted" manuscripts. 


\title{
Multiscale Exploration and Experimental Insights into Separating Neutral Heterocyclic Nitrogen Compounds using $[\mathrm{emim}]\left[\mathrm{NO}_{3}\right]$ as an Extractant
}

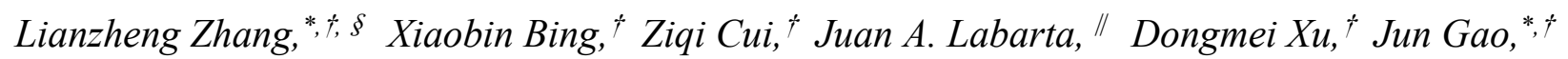 \\ Shixue Zhou, ${ }^{\dagger}$ Yinglong Wang ${ }^{*}$
}

${ }^{\dagger}$ College of Chemical and Biological Engineering, Shandong University of Science and Technology, 579 Qianwangang Road, Qingdao 266590, P. R. China

$\S$ Shandong Key Laboratory of Biochemical Analysis; College of Chemistry and Molecular Engineering, Qingdao University of Science and Technology, 53 Zhengzhou Road, Qingdao,

\author{
266042, P. R. China \\ $\$$ College of Chemical Engineering, Qingdao University of Science and Technology, 53 \\ Zhengzhou Road, Qingdao, 266042, P. R. China \\ " Department of Chemical Engineering, University of Alicante, Alicante, 03080, Spain
}

\author{
*Corresponding Author \\ Jun Gao, E-mail: gao@sdust.edu.cn, ORCID: 0000-0003-1145-9565 \\ Lianzheng Zhang, E-mail: zhanglz@sdust.edu.cn, ORCID: 0000-0003-4827-7941
}




\begin{abstract}
As valuable chemical materials, the heterocyclic nitrogen compounds are widely found in nature, and they are in common use. In this paper, the multiscale interaction mechanisms between 1-ethyl-3-methylimidazolium nitrate $\left([\mathrm{emim}]\left[\mathrm{NO}_{3}\right]\right)$ and representative heterocyclic nitrogen compounds (pyrrole and indole) during the extraction process are investigated. By combining theoretical and experimental research, first, the ionic liquid and its corresponding composite systems are studied with a multiscale microscopic method. With the help of quantum chemical calculation and molecular dynamics simulation, the polarity and the difference of the interactions of $[\mathrm{emim}]\left[\mathrm{NO}_{3}\right]$ and nitrogen compounds as well as the mechanism of the separation process are explored. Additionally, the mechanism of the separation process and its effects are evaluated through phase equilibrium measurement and extraction experiment. The results reveal the highly selective separation of neutral pyrrole and indole and lay a solid foundation for the development of a new extraction process for complex systems containing neutral heterocyclic nitrogen compounds.
\end{abstract}

Keywords: Heterocyclic Nitrogen Compounds, Ionic Liquids, Extraction, Molecular dynamics, Quantum Chemistry, Liquid-Liquid Equilibrium 


\section{Introduction}

The organic nitrogen-containing compounds ( $N$-compounds) are widely spread over the world and are important compounds. Many $N$-compounds, such as alkaloids, have biological activity and some, such as amino acids and many drugs, are indispensable for life. Dyes are also composed of $N$-compounds, and some $\mathrm{N}$-compounds are commonly used chemical materials, such as pyrrole, indole, pyridine, quinoline, nitrile and their derivatives. The above materials are derived mainly from coal-based products or in industrial petroleum refining. The $N$-compounds in coal-based products and petroleum refining are present mainly as heterocyclic aromatic $N$-compounds. ${ }^{1}$ Those heterocyclic $N$-compounds can be classified as basic (such as pyridine, acridine and quinoline) and nonbasic (such as pyrrole, indole, carbazole and derivatives thereof). In view of the nature and application, considerable economic value can be created by using appropriate methods to separate those $N$-compounds. Simultaneously, some $N$-compounds present in fuel oils are discharged into the atmosphere as $\mathrm{NO}_{x}$ as the oil is burned, causing air pollution and acid rain. ${ }^{2-3}$ With the increasing pressure on environmental protection, more stringent requirements are imposed on the cleaner fuel production. Or exist in nature, giving rise to pollute water. ${ }^{4-7}$ Therefore, it is important to increase the efficiency of separating or removing $N$-compounds.

Similarly, great progress has been made in the study of separating or removing the $N$-compounds from different sources. High content of heterocyclic nitrides is confirmed to be one of the more than 500 compounds identified in coal tar, which is one of its main sources. ${ }^{8-9}$ In view of the vast coal tar output in countries utilizing coal as the main energy source, it is urgent to make reasonable and effective use of the coal tar. ${ }^{10}$ Moreover, similar types of extraction studies for removing both 
basic and non-basic $N$-compounds from fuels has attracted considerable attention. Hence, techniques such as acid washing, ${ }^{6}$ alkali fusion, ${ }^{11}$ ion-exchange resin separation, ${ }^{12}$ and solvent extraction (such as by volatile organics, ${ }^{13-14}$ ionic liquids ${ }^{15}$ or deep eutectic solvents ${ }^{16-18}$ ) are employed. Noncatalytic techniques were developed for separating or removing $N$-compounds from different sources in some special processes. However, in view of the excellent properties and some similar applications, ionic liquids (ILs) have been adopted to separate $N$-compounds from different sources with a high selectivity in the last decade or so. ${ }^{8,19-24}$ Moreover, large numbers of similar studies have reported the denitrification process using different kinds of ILs. ${ }^{25-28}$ All the above studies demonstrated that the ILs are commonly recognized in the separation field, and the relevant comparison was reviewed in the literature ${ }^{8,24,29}$. After reviewing those studies, less interest was focused on expounding separation theory and its phase equilibrium, and of course, its multiscale mechanisms are unclear.

The process of separating $N$-compounds was viewed as liquid-liquid extraction, and most of the reported extraction processes using ILs show relatively high extraction effects and selectivity. Several conceivable mechanisms such as the formation of clathrates between the ILs and solvents, indicate that the ordered and extended stacking structure repeating units have been suggested as ways to achieve good separation, ${ }^{30-31}$ the $\pi-\pi$ interaction existing in IL extractants and aromatic compounds was responsible for the efficient extraction, ${ }^{32-33}$ or the acidity or alkalinity. ${ }^{34}$ of the adopted ILs. In addition, the hydrogen bond formed between the polar groups in ILs and the target components ${ }^{9,35-36}$ was another acceptable illustration of the separation process. All the above results were confirmed experimentally, but only a very few investigations were devoted to visual 
elaboration of the mechanism of the separation process. To explore the extraction mechanism at a molecular level, quantum chemical (QC) calculation or molecular dynamics (MD) simulation have been employed by fewer researchers. Some basic molecular insights for the interactions between the molecules studied can be revealed for the investigated systems containing $N$-compounds. Moreover, the multiscale investigations can also contribute to the understanding of the extraction mechanism from different perspectives. ${ }^{37-39}$ Ramalingam ${ }^{40}$ studied the fundamental nature of the interaction between pyrrole/ pyridine with $[\mathrm{emim}]\left[\mathrm{EtSO}_{4}\right]$ using DFT theory and sigma profile analysis via the COSMO-RS approach. Bhoi et al. ${ }^{41}$ investigated the interaction of ILs with different commercial cations using the HOMO-LUMO energies, quantum descriptors and IDAC with the COSMO-RS model, and two ILs were recommended for the dissolution of bituminous and anthracite coal. Verdía et al. ${ }^{42}$ provided different cation substituent pyridinium dicyanamide ILs, and the QC calculations indicated that the hydrogen bond donor character of the cation was successfully tuned by an adequate substitution during the extraction of $N$-compounds from fuels. This result was also observed in a COSMO-RS study. Naik et al. ${ }^{43}$ measured the phase equilibrium data and compared these data with the MD simulation data for the separation of quinoline from heptane using a low-cost DES. Then, the interaction energies of the corresponding molecules, the structural properties such as RDF, SDF, and average number of hydrogen bonds were computed. Consequently, after clarifying the extraction mechanism not only through experiments but also from multiscale perspectives, it would be very helpful for us to identify increasingly reliable ILs that can be applied to extract $N$-compounds from different sources. 
After consulting the literature for separation of $N$-compounds from different sources ${ }^{8}$ and referring to our previous studies in IL screening and extraction exploration, ${ }^{19,}, 24$ there is no doubt that ILs with certain functional groups can act as potential extractants. Moreover, this research is driven by popular areas of research and by practical needs in industry. As Welton ${ }^{44}$ summarized the ways in which solvents may make chemical processes more sustainable from a series of industrial examples, the solvents in the separation process should lead to higher quality products or improve product separation etc. So, it is extremely important to achieve a higher selectivity and efficiency for the separation process. In view of the advantages of ILs, the easily prepared functional ILs 1-ethyl-3-methylimidazolium nitrate ([emim] $\left.\left[\mathrm{NO}_{3}\right]\right)$ are considered to extract the basic and abundance pyrrole and indole based on the polarity analysis by the COSMO-SAC model. ${ }^{19}$ Meanwhile, combining QC calculation and MD simulation with the experimental study, the relationship between $[\mathrm{emim}]\left[\mathrm{NO}_{3}\right]$ itself and its complex systems with the representative $N$ compounds was researched on the multiscale. The multiscale mechanisms for the extraction process were explored, which can clearly explain the high selectivity of the extraction process and provide a guide for the further application. In addition, the liquid-liquid equilibrium data from ternary systems (methylbenzene + pyrrole/indole $\left.+[\mathrm{emim}]\left[\mathrm{NO}_{3}\right]\right)$ at $T=298.15 \mathrm{~K}$ and $101.3 \mathrm{kPa}$ were measured to confirm the effect from the perspective of phase equilibrium. Further, two random feed points were simulated and compared with the experimental tie-line data to understand their phase behavior. The commonly used NRTL activity coefficient model was applied to regress the measured tie-lines and obtain the binary interaction parameters. Finally, necessary extraction experiments were systematically optimized by considering the mass ratio of $[\mathrm{emim}]\left[\mathrm{NO}_{3}\right]$ to 
model oil, extraction temperature and time. The investigated $[\mathrm{emim}]\left[\mathrm{NO}_{3}\right]$ is thus identified as a practical IL extractant with improved separation capacity and selectivity for pyrrole and indole.

\section{Computational Section}

\section{Molecular Dynamics Simulation Details}

The microscopic interactions between $[\mathrm{emim}]\left[\mathrm{NO}_{3}\right]$ and $N$-compounds was studied by $\mathrm{MD}$ simulation, which explored the simulation results of the actual systems at the molecular level. All simulation results in this work were accomplished using the GROMACS package ${ }^{45}$ at $298.15 \mathrm{~K}$. The required force field parameters were generated based on the Generalized Amber Force Field (GAFF) ${ }^{46}$ in the ANTERCHAMBER ${ }^{47}$ module of those compounds. To block the bonds containing hydrogen atoms, the LINCS ${ }^{48}$ algorithm was used at one atmosphere with a V-rescale thermostat ${ }^{49}$ and a Parrinello-Rahman barostat. ${ }^{50}$ The accepted PME method was used and set the cutoff radius of $12 \AA$ for intermolecular long-range electrostatic interaction, while the time step was set at $1 \mathrm{fs}$, and the periodic boundary condition (PBC) was used in all simulation systems. Further, the neighbor scheme was treated by the Verlet algorithm. Then, those settings were acknowledged by proving the MD simulated density of [emim] $\left[\mathrm{NO}_{3}\right]\left(1.26 \mathrm{~g} / \mathrm{cm}^{3}\right)$ at $293.15 \mathrm{~K}$ under atmospheric pressure with the reported density value $\left(1.28 \mathrm{~g} / \mathrm{cm}^{3}\right)$, and the simulated density values agreed with the experimental data. As mentioned above, the original structures of [emim] $\left[\mathrm{NO}_{3}\right], N$-compound and methylbenzene obtained from the QC optimization were then used directly to construct the simulated systems by PACKMOL ${ }^{51}$ according to a certain number of 
proportions. Additionally, $[\mathrm{emim}]\left[\mathrm{NO}_{3}\right]$ and methylbenzene were distributed in two separated boxes, named the IL and organic phase, and $N$-compound was dispersed into those two phases.

To restore the real extraction environment as much as possible, the number of molecules were determined in light of the original feed composition. During the MD simulation, 50000 steps of minimization were adopted. Then, the system was heated to $298.15 \mathrm{~K}$ for $0.5 \mathrm{~ns}$, in a stepwise fashion. When the desired temperature was achieved, the 5 ns isothermal-isobaric NPT ensemble was equilibrated. Subsequently, the $50 \mathrm{~ns}$ NVT ensemble was running to achieve clear phase separation data. As time extended, $N$-compound was no longer moved from the methylbenzene phase to the ILs phase. The trajectory data were saved for structural and transport analysis at every 500 ps by the Visual Molecular Dynamics (VMD) package. ${ }^{52}$

\section{Quantum Chemical Calculation Details and the COSMO-SAC Model}

The intermolecular interactions for the above system were also studied by QC calculation. In chemistry and materials science, the density functional theory (DFT) is pyramidally adopted to investigate, predict complex behaviors or interactions at the molecular level. For the convenience of computation, the $\mathrm{Dmol}^{3}$ module in the Accelrys Material Studio was adopted from the commonly used software or a program such as Turbomole and Gaussian. The computational settings are described in detail and expressed in Part 1 in the Supporting Information. Then, bond length, interaction energy, and deformation charge density maps were calculated.

For the purpose of obtaining the polarity information for each component, the $\sigma$-profile analysis was done by using the COSMO-SAC model. The detailed explanation of the open source COSMOSAC model and its calculations were introduced in our previous study and are not discussed here. 
53-54 After the final optimized geometries were obtained, the COSMO information for [emim] $\left[\mathrm{NO}_{3}\right]$, pyrrole, indole, and methylbenzene were generated. Then, the $\sigma$-profile data, which are presented in Table S3, was generated. The detailed settings and parameters are also listed in Part 1 in the Supporting Information.

\section{Experimental Section}

\section{Chemicals and LLE Measurements}

The reagents used in this study were all obtained commercially, and the purities were all supplied by the suppliers. Basic information such as the chemical formula structure, molecular weights, purity, CAS number, and density are listed in Table 1. The LLE tie-line data for the systems of methylbenzene + pyrrole/indole $+[\mathrm{emim}]\left[\mathrm{NO}_{3}\right]$ were determined at $T=298.15 \mathrm{~K}$ and $101.3 \mathrm{kPa}$ to verify the computational results. The multiple-use LLE device was adopted for the LLE experiments both in our previous study and in the work of other researchers. ${ }^{24,}{ }^{29,55-61}$ The LLE measurements procedure and analysis are presented in detail in Part 2 in the Supporting Information. Furthermore, the NRTL model was used to regress the tie-line data that were determined, and the recognized Graphical User Interface (GUI-MATLAB) raised by ReyesLabarta ${ }^{62-65}$ was adopted to evaluate the experimental tie-line data.

Table 1. Detailed information of the reagents used.

\begin{tabular}{cccccccc}
\hline Structure & Abbreviation & $C A S \mathrm{No}$. & $\mathrm{M} / \mathrm{g} \cdot \mathrm{mol}^{-1}$ & $\begin{array}{c}\text { Density } \\
/ \mathrm{g} \cdot \mathrm{cm}^{-3}\end{array}$ & $\begin{array}{c}\text { Water } \\
\text { content } / p p m\end{array}$ & $\begin{array}{c}\text { Halogen } \\
\text { content } / p p m\end{array}$ & $\begin{array}{c}\text { Purity } \\
(\mathrm{w} \%)\end{array}$ \\
\hline $\begin{array}{c}\text { 1-ethyl-3-methyl } \\
\text { imidazolium nitrate }\end{array}$ & $\begin{array}{c}143314- \\
14-1\end{array}$ & 173.08 & 1.28 & $<1000$ & $<1000$ & $\geq 99 \%$ \\
\hline
\end{tabular}




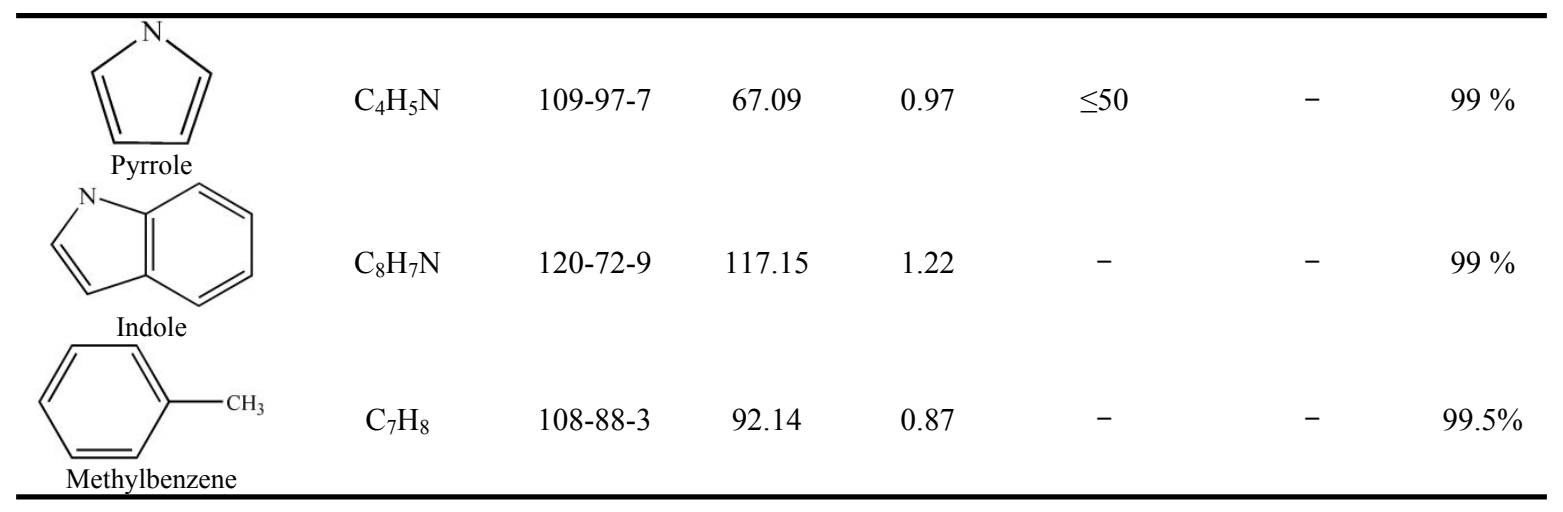

Extraction Experiments

The apparatus and procedure for the liquid-liquid extraction experiments were adopted and are described extensively in previous studies. ${ }^{8-9,19}$ The commercially obtained $[\mathrm{emim}]\left[\mathrm{NO}_{3}\right]$ was mixed with the model oil using a customized jacketed glass vessel at the set temperature for 30 min, then enough time was allowed to let the mixtures settle. Before the phase equilibrium state was reached, all the possible disturbances must be prevented. Then, the GC was used to quantitatively analyze the content. The detailed procedures and analytical methods are also presented in Part 2 in the Supporting Information.

\section{Results and Discussion}

There has been substantial utilization of ILs in the extraction process. Several possible mechanisms have been proposed by scholars, as mentioned in the introductory section, that can explain the good separation ability and selectivity of ILs. According to the strong polarity characteristics of ILs, the generation of the intermolecular interactions with the targeted compounds provide most function for the ILs. These interactions are reversible and would be restored via the back-extraction process or by simply being heated. Thus, it is worthwhile to extract 
typical pyrrole, indole and its derivatives from coal tar or diesel fuels using easily prepared ILs by the formation of at least one hydrogen bond during the extraction process.

The approved COSMO-SAC model was adopted to evaluate the polarity of the selected [emim] $\left[\mathrm{NO}_{3}\right], N$-compounds and methylbenzene in this work. The calculated results of the $\sigma$ profile analysis are presented in Figure 1, from which the strong polar nitrate anion is shown to have the possibility of acting as a hydrogen bond accepter. The screening charge distribution of [emim $]\left[\mathrm{NO}_{3}\right]$ is $[-0.015,+0.019]$ e/ $\AA^{2}$. The studied $N$-compounds have the opposite polarity and can be used as a hydrogen bond donor during the extraction process. However, methylbenzene does not exhibit any strong polarity and could not form any interactions with the previously listed components. Therefore, the extraction of $N$-compounds by $[\mathrm{emim}]\left[\mathrm{NO}_{3}\right]$ can be confirmed to a certain degree. In addition, the electrostatic potential obtained based on the optimized structures is also presented in Figure 1. As shown in the figure, red and blue indicate the negative and the positive regions, respectively. The darker the color, the larger the electrostatic potential values. A strong negative potential of nitrate anion and a strong positive potential of the $\mathrm{N}$-compounds can be seen, forming the interactions with each other. Moreover, the interaction strength can directly relate to the electrostatic potential. 


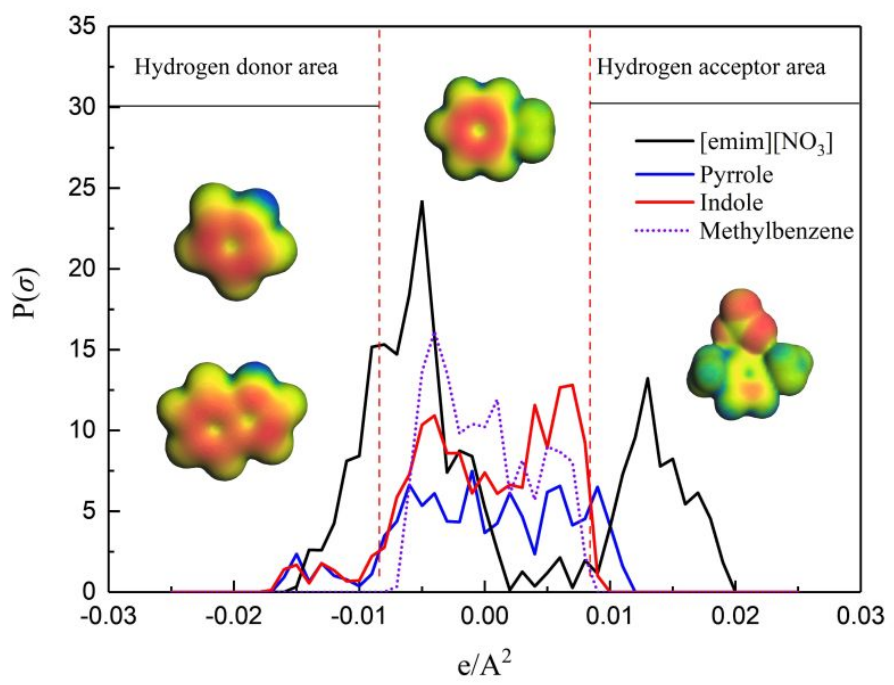

Figure 1. The $\sigma$-profile comparison of pyrrole, indole, methylbenzene and [emim] $\left[\mathrm{NO}_{3}\right]$.

\section{Liquid-Liquid Equilibrium Tie-Line Data and the Comparison of the Two MD Simulated Results}

Considering the $\sigma$-profile analysis results, a liquid-liquid equilibrium experiment was adopted to further study the possibilities of the selected extractant at room temperature. Consequently, the ternary system tie-line data (methylbenzene + pyrrole/indole $\left.+[\mathrm{emim}]\left[\mathrm{NO}_{3}\right]\right)$ were measured at $298.15 \mathrm{~K}$ under $101.3 \mathrm{kPa}$. In the meantime, the experimental distribution coefficient $(D)$ and selectivity $(S)$ of the above two systems were calculated, reflecting the extraction performance of [emim] $\left[\mathrm{NO}_{3}\right]$, and expressed in the following:

$$
\begin{aligned}
& D=\frac{x_{2}^{\mathrm{II}}}{x_{2}^{\mathrm{I}}} \\
& S=\frac{x_{2}^{\mathrm{II}} x_{1}^{\mathrm{I}}}{x_{2}^{\mathrm{I}} x_{1}^{\mathrm{II}}}
\end{aligned}
$$

where $x$ refers to the mole fraction. Superscripts I and II are used to express the organic phase and IL phase, respectively, and subscripts 1, 2, and 3 represent methylbenzene, $N$-compounds, and 
[emim] $\left[\mathrm{NO}_{3}\right]$, respectively. The measured LLE data with the calculated $D$ and $S$ values are presented in Table 2.

Table 2. Experimental LLE data (mole fraction), distribution coefficients $(D)$ and selectivity $(S)$ for methylbenzene (1) + pyrrole/indole (2) $+[\mathrm{emim}]\left[\mathrm{NO}_{3}\right](3)$ at $T=298.15 \mathrm{~K}$ under $101.3 \mathrm{kPa}$.

\begin{tabular}{|c|c|c|c|c|c|}
\hline \multicolumn{2}{|c|}{ Organic phase } & \multicolumn{2}{|c|}{ IL phase } & \multirow{2}{*}{$D_{2}$} & \multirow{2}{*}{$S$} \\
\hline$x_{1}^{\mathrm{I}}$ & $x_{2}^{\mathrm{I}}$ & $x_{1}^{\mathrm{II}}$ & $x_{2}^{\mathrm{II}}$ & & \\
\hline \multicolumn{6}{|c|}{ Methylbenzene (1) + Pyrrole (2) $+[\mathrm{emim}]\left[\mathrm{NO}_{3}\right](3)$} \\
\hline 0.9764 & 0.0236 & 0.2366 & 0.2360 & 9.99 & 41.20 \\
\hline 0.9648 & 0.0352 & 0.2367 & 0.3237 & 9.19 & 37.46 \\
\hline 0.9541 & 0.0459 & 0.2379 & 0.4087 & 8.90 & 35.71 \\
\hline 0.9434 & 0.0566 & 0.2411 & 0.4717 & 8.34 & 32.62 \\
\hline 0.9272 & 0.0727 & 0.2425 & 0.5027 & 6.91 & 26.43 \\
\hline 0.9139 & 0.0861 & 0.2691 & 0.5096 & 5.92 & 20.10 \\
\hline 0.8772 & 0.1224 & 0.2976 & 0.5052 & 4.13 & 12.17 \\
\hline 0.8599 & 0.1392 & 0.3283 & 0.4915 & 3.53 & 9.24 \\
\hline
\end{tabular}

Methylbenzene (1) + Indole (2) $+[$ emim $]\left[\mathrm{NO}_{3}\right](3)$

\begin{tabular}{llllll}
0.9837 & 0.0162 & 0.0752 & 0.5033 & 30.98 & 405.08 \\
0.9680 & 0.0320 & 0.1230 & 0.5293 & 16.55 & 130.23 \\
0.9654 & 0.0344 & 0.1332 & 0.5400 & 15.70 & 113.85 \\
0.9472 & 0.0526 & 0.1556 & 0.5576 & 10.60 & 64.52 \\
0.9367 & 0.0630 & 0.1853 & 0.5700 & 9.04 & 45.69 \\
0.9061 & 0.0936 & 0.2125 & 0.5789 & 6.19 & 26.38 \\
0.8788 & 0.1202 & 0.2354 & 0.5857 & 4.87 & 18.18 \\
0.8428 & 0.1548 & 0.2515 & 0.5904 & 3.81 & 12.78 \\
\hline
\end{tabular}

a Standard uncertainties $u$ are $u(T)=0.05 \mathrm{~K}, u(P)=1 \mathrm{kPa}, u(x)=0.006$.

As shown in Table 2, the IL extractant content in the organic phase of the above two systems was very low. However, the selectivity was high, and this high selectivity can be used to evaluate the extracting ability from the mixtures. In addition, the corresponding triangular diagrams, belonging to Treybal's type 1, are plotted with the feed composition and tie-line. The corresponding phase diagrams are shown in Figure S1 and S2 in the Supporting Information. The $D$ and $S$ values for the studied systems are all greater than unity, which means that $[\mathrm{emim}]\left[\mathrm{NO}_{3}\right]$ have the ability to severed as good extractant for the extraction of pyrrole and indole. By 
comparing the $D$ values, both pyrrole and indole can distribute in the equilibrium phase well, and the difference is relatively small. But for $S$ values, indole is larger than pyrrole especially when $x_{2}^{I}$ is small. This means that it is feasible to extract pyrrole and indole by $[\mathrm{emim}]\left[\mathrm{NO}_{3}\right]$, but better extraction ability was shown for indole. This result was in accordance with the QC computational results listed in Table 4 in the following part.

Meanwhile, the widely recognized nonrandom two-liquid (NRTL) activity coefficient model was used to correlate the experimental tie-line data. Binary interaction parameters were obtained by fixing the nonrandomness parameter $\left(\alpha_{\mathrm{ij}}=0.2\right)$ with the help of a MATLAB program, and the detailed description was illuminated in our previous work. ${ }^{24,66}$ The regressed results are listed in Table S4 in the Supporting Information. The GUI-MATLAB raised by Reyes-Labarta ${ }^{62-65}$ was adopted to assure that the parameters obtained are coherent with the experimental results. The verified results for the NRTL model are also expressed in Part 3 in the Supporting Information.

Based on the experimental tie-line data, the MD simulated tie-line data were simulated referring to the experimental feed composition. Considering the restrictions, only two feed compositions were adopted to simulate the tie-lines and compared with the experimental extract and the raffinate phase for the pyrrole/indole-containing system, respectively. Moreover, a total of 1400 molecules were adopted for the MD simulation, the details number of molecules along with its mole fraction for the MD simulation are listed in Table 3. The comparison between the experimental results and the simulated results are also presented in Figure 2, and its corresponding data are listed in Table S5. The two simulated and regressed sets of tie-line data are distributed on both sides of the 
experimental value with small differences, which indicates that both the simulated and regressed tie-line data are receivable.

Table 3. Mole fractions and number of molecules in MD simulation for the two systems.

Figure 2 Experimental, NRTL correlated and MD simulated tie-line data for the system of methylbenzene + pyrrole (a)/indole $(b)+[\operatorname{emim}]\left[\mathrm{NO}_{3}\right] \cdot(\bullet,-$, black $)$, experimental data, $(\Delta,---$, blue) regressed by NRTL, $(\diamond,-\cdots, \cdots-)$, MD simulated data, («, red), feed composition.

\section{Molecular Dynamics Simulation Analysis}

By comparing the LLE tie-line data and the MD simulated data, the potential of the $[\mathrm{emim}]\left[\mathrm{NO}_{3}\right]$ for extracting $\mathrm{N}$-compounds is confirmed, and the reliability of the MD simulation results is also confirmed. Therefore, to clarify the intermolecular interactions between $[\mathrm{emim}]\left[\mathrm{NO}_{3}\right]$ and $N$ - 
compounds, the radial distribution function and spatial distribution function etc. were adopted to investigate the microstructure and molecular movement of the extraction process.

\section{Radial Distribution Function}

The radial distribution function (RDF) is an important function used to characterize the local microstructure of a fluid. Therefore, the RDF can be used not only to study the structural packing but also to describe the interactions between different molecules. Referenced to the $\sigma$-profile analysis based on the COSMO-SAC, a hydrogen bond can form between indole and the strongly polar $[\mathrm{emim}]\left[\mathrm{NO}_{3}\right]$. Therefore, the oxygen atoms $(\mathrm{ON}, \mathrm{ON} 1$, and $\mathrm{ON} 2)$ of the nitrate anion, the hydrogen atom (HI6) of indole and (HM6) of methylbenzene, hydrogen atom (HE2) and carbon atoms (CE2, CE3, CE4, and CE5) of the emim cation and the nitrogen atom (NI) of indole were adopted to generate the RDF plots. The detailed atom notations of different molecules are shown in Figure 3, and the atom-atom RDF plots between the above atoms are presented in Figure 4.
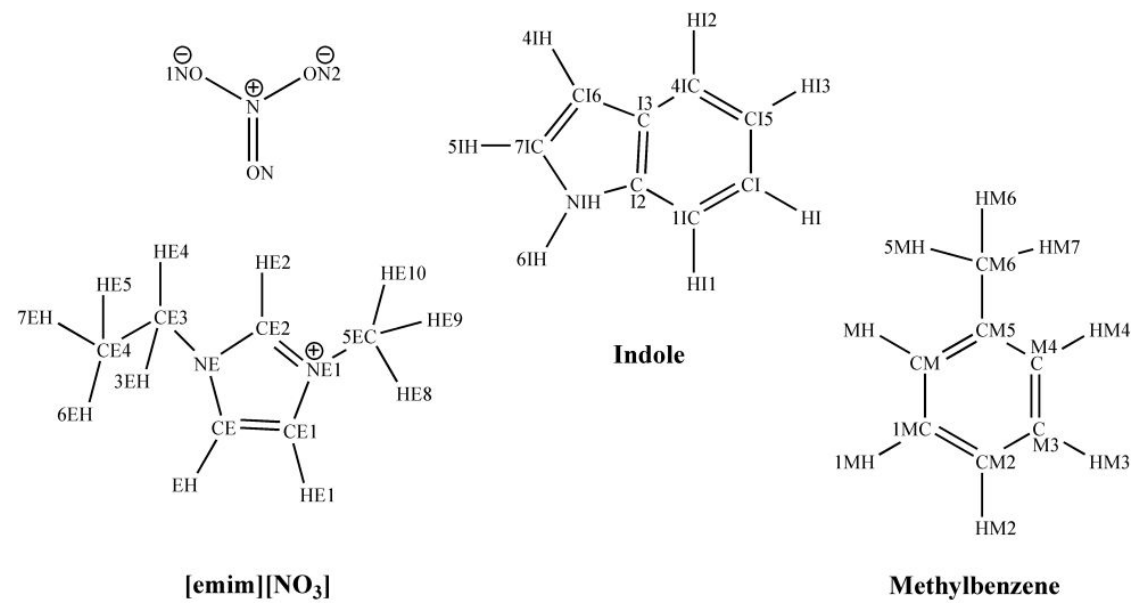

Figure 3. Structures with atom notations of different molecular species.

The detailed RDF results between indole and $[\mathrm{emim}]\left[\mathrm{NO}_{3}\right]$ are expressed in Figure $4(\mathrm{a}-\mathrm{b})$ from which a well-defined strong first solvation peak was shown, revealing the stronger interactions 
between $[\mathrm{emim}]\left[\mathrm{NO}_{3}\right]$ and indole than with the solvent methylbenzene. In Figure 4 (a), for the purpose of qualitatively expounding the hydrogen bond between $[\mathrm{emim}]\left[\mathrm{NO}_{3}\right]$ and indole, three oxygen atoms in the nitrate anion were adopted to generate the RDF plot with hydrogen atoms in the indole and methylbenzene, respectively. The RDF peak between the oxygens of the nitrate (ON, ON1, and ON2) and the hydrogen of indole (HI6) reached a distance of $1.84 \AA, 2.12 \AA$, and $2.10 \AA$ A respectively, which are significantly different from the hydrogen values of methylbenzene (HM6). While the interactions between indole and nitrate are strong, there were no interactions observed between methylbenzene and nitrate. Moreover, the RDF peak height, $g(r)$, of HI6-ON is obviously higher than the RDF peak height, $g(r)$ of the other two oxygen atoms, indicating a stronger interaction. The degree of interaction for the three oxygens in nitrate is $\mathrm{ON}>\mathrm{ON} 1 \approx \mathrm{ON} 2$.
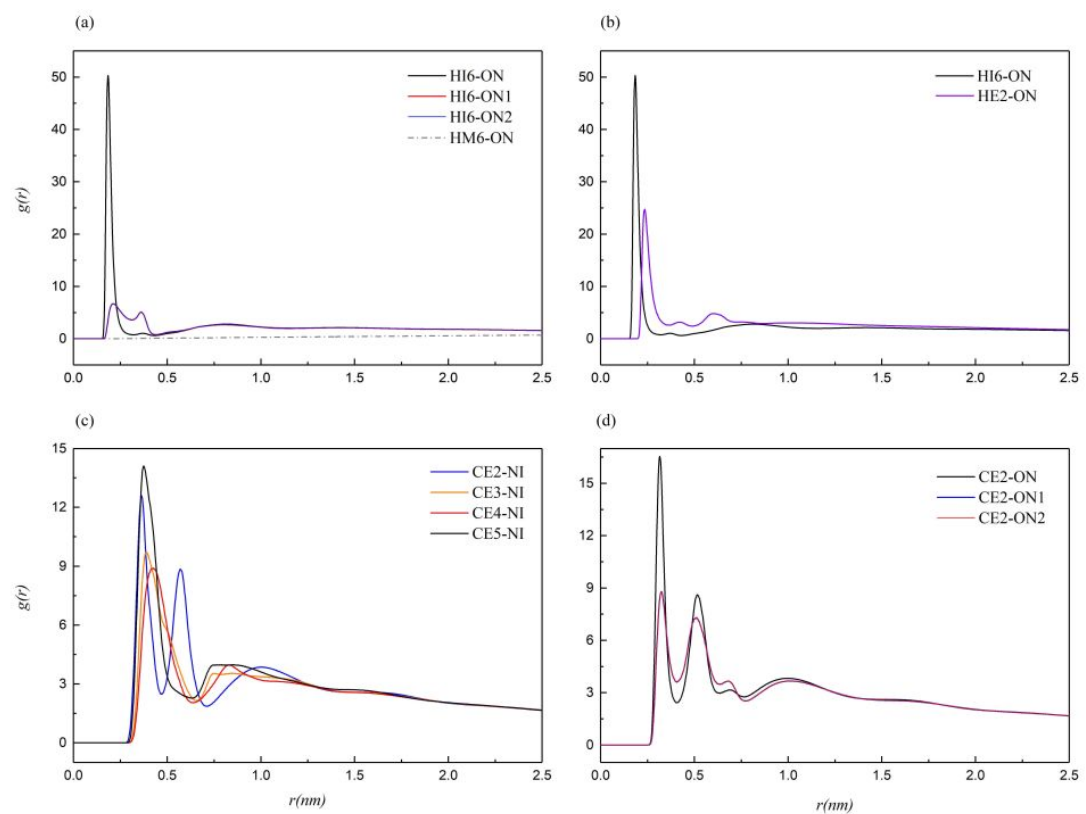

Figure 4. Atom-atom RDF plots between the different molecules in the methylbenzene + indole + $[\mathrm{emim}]\left[\mathrm{NO}_{3}\right]$ ternary system. 
And this can also be analyzed by the average hydrogen bonding. The average number of indolenitrate hydrogen bonding was presented in Figure 5, of which 50 ns were adopted. A higher number of hydrogen bonding of indole with nitrate anion were established. As expected, there are no hydrogen bonding interactions between methylbenzene and nitrate were noticed. Meanwhile, as shown in Figure 4 (b), the HI6-ON presented a higher $g(r)$ peak than the HE2-ON, and the distance of HE2-ON is $2.36 \AA$, which is larger than $1.84 \AA$, thus reflecting that a significant distribution of nitrate anion occurs around indole. The same phenomenon was observed by the spatial distribution function, as discussed below.

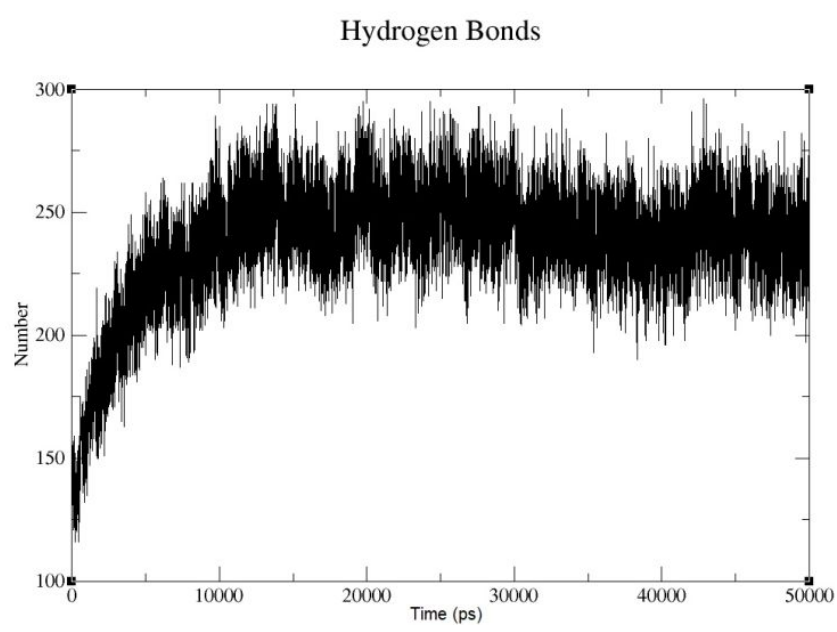

Figure 5. Average number of indole-nitrate per indole molecule as a function of simulation time.

Similarly, the RDF plots for different sites of the IL extractant, [emim] $\left[\mathrm{NO}_{3}\right]$, are also presented, which gives a preliminary analysis of the IL structure and provides a reliable guide for the subsequent calculations. In Figure 4 (c), for the purpose of exploring the sites of the nitrate anion in $[\mathrm{emim}]\left[\mathrm{NO}_{3}\right]$, the oxygen atoms $(\mathrm{ON})$ in the nitrate anion were adopted to generate the RDF plot with carbon atoms, CE2, CE3, CE4, and CE5 in the emim cation. The RDF peak between ON 
and CE2, CE3, CE4, and CE5 was reached at a distance of $3.62 \AA, 3.90 \AA, 4.26 \AA$, and $3.74 \AA$, respectively, indicating that the nitrate anion is distributed on the methyl side. Considering the differences of the oxygen atoms in the nitrate anion, the RDF plots between those three oxygen atoms and CE2 are expressed in Figure 4 (d). The RDF peak between CE2 and ON, ON1, and ON2 reached at a distance of $3.16 \AA, 3.24 \AA$, and $3.26 \AA$, respectively, indicating that the ON atom of the nitrate anion is close to CE2. Therefore, the relative positions of the cation and anion of [emim] $\left[\mathrm{NO}_{3}\right]$ can be preliminary confirmed.

\section{Spatial Distribution Function}

Compared with the RDF, the spatial distribution function (SDF) was adopted to describe the density distribution characteristics of the environment of molecules around the target center molecule in three-dimensional space. For the system investigated in this work, the SDF plots were produced using the TRAVIS ${ }^{67}$ software package, and they are shown in Figure 6.

As seen in Figure 6 (a), the acting nitrate anion was used to generate the SDF plot surrounded by indole and methylbenzene. The active $\mathrm{O}$ atom of the anion molecule was surrounded by the indole molecule, but no interactions with methylbenzene can be seen. Therefore, in accordance with the RDF plot analysis, a hydrogen bond was confirmed between the nitrate and the indole. Meanwhile, combined with the RDF plot in Figure 4 (b), a significant distribution of nitrate anion was surrounded by the indole rather than the emim cation. This phenomenon can also be explained by the SDF plot in Figure 6 (b), where the nitrate anion was more highly distributed around the center indole molecule than the emim cation, indicating that the intermolecular interaction between 
the nitrate anion and the indole was larger than the intermolecular interaction between the emim cation and the indole. For pyrrole system, similar results can be seen from Figure 6 (c) and (d).

(a)

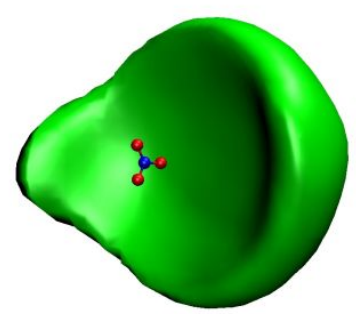

(c)

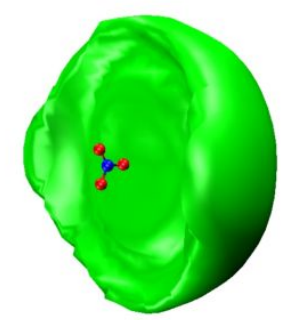

(b)

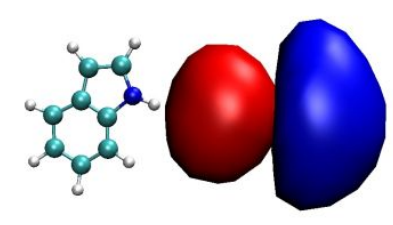

(d)

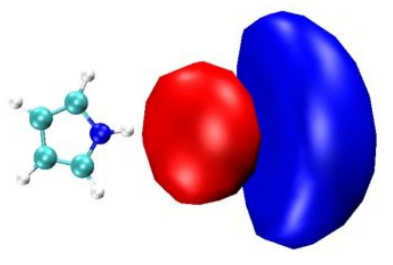

Figure 6. SDF plots of methylbenzene + indole/pyrrole $+[\mathrm{emim}]\left[\mathrm{NO}_{3}\right]$ ternary system. (a) indole/(c) pyrrole (green) around nitrate anion at an isovalue of $1.15 / 1.57$ particle $\mathrm{nm}^{-3}$, nitrate anion (red) and emim cation (blue) around the (b) indole/(d) pyrrole at isovalues of 2 and 1.85/2.55 and 2.25 particle $\mathrm{nm}^{-3}$, respectively.

\section{Quantum Chemical Calculation Analysis}

Weak molecular interactions may exist between $[\mathrm{emim}]\left[\mathrm{NO}_{3}\right]$ and $N$-compounds based on the simulation results and the tie-line data measurement. To clarify the interactions, the intermolecular forces between the $[\mathrm{emim}]\left[\mathrm{NO}_{3}\right]$ and $N$-compounds were further verified at the molecular level, which can provide some basic analysis to support the MD simulation results. Therefore, the charge density analysis combined with the bond length and energy were adopted to illuminate the 
extraction process from this perspective. Moreover, through the analysis of the above data, the hydrogen bond donor and acceptor relationship could be shown. The relevant molecules connected to the heteroatoms in $N$-compounds probably formed a hydrogen bond with the [emim] $\left[\mathrm{NO}_{3}\right]$. Then, the interactions that were formed were examined to verify the hypothesis.

\section{Bond Length and Energy}

Based on the confirmation of the preliminary relative position for the cation and anion of [emim] $\left[\mathrm{NO}_{3}\right]$, the geometry for the $N$-compounds, $[\mathrm{emim}]\left[\mathrm{NO}_{3}\right]$ and their optimized complexes and two optimal complexes are presented in Figure 7. Furthermore, the BSSE-corrected interaction energies for these two complexes are calculated and listed in Table 4.

(a)

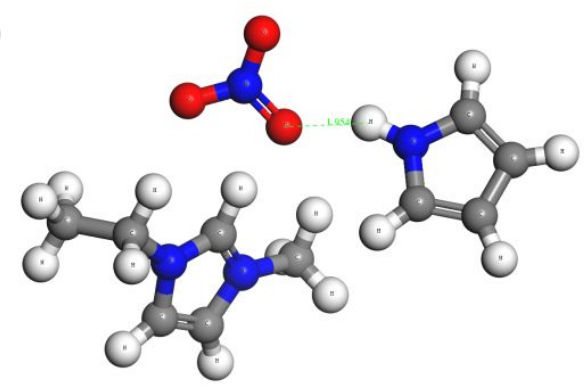

(b)

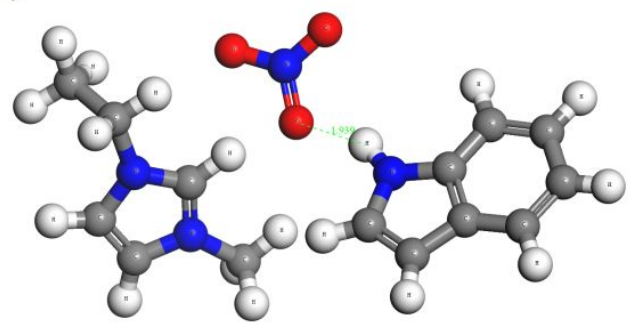

Figure 7. Bond length for $[\mathrm{emim}]\left[\mathrm{NO}_{3}\right]$ with pyrrole (a) and indole (b).

As the configuration of these two complexes shows, the interaction distances between pyrrole/indole and nitrate are $1.975 \AA$ and $1.934 \AA$, which is less than the sum of the Van der Waal's radii of $\mathrm{H}, 1.30 \AA$, and $\mathrm{O}, 1.72 \AA$, respectively, reflecting that distinct intermolecular interactions exist between pyrrole/indole and the nitrate anion. Moreover, to quantitatively describe the interaction between the complexes, the interaction energies of $[\mathrm{emim}]\left[\mathrm{NO}_{3}\right]$ with pyrrole and indole were calculated. The interaction energies are $-35.069557 \mathrm{~kJ} / \mathrm{mol}$ and - 
$36.117233 \mathrm{~kJ} / \mathrm{mol}$, and they belong to a stronger hydrogen bond. Consequently, the $\mathrm{N}-\mathrm{H} \cdots \mathrm{O}$ hydrogen bonds can be confirmed by combining the bond length and energy results.

Table 4. The revised BSSE interaction energy of compounds and complexes that have been studied.

\begin{tabular}{lccc}
\hline System & $E\left(\right.$ hartree $\left.^{\mathrm{a}}\right)$ & $E_{B S S E}\left(\right.$ hartree $\left.^{\mathrm{a}}\right)$ & $\Delta E\left(\mathrm{~kJ}^{\mathrm{mol}} \mathrm{mol}^{-1}\right)$ \\
\hline Pyrrole & -210.239711 & - & - \\
Indole & -363.930970 & - & - \\
Methylbenzene & -271.641264 & - & - \\
{$\left[\right.$ emim] $\left[\mathrm{NO}_{3}\right]$} & -625.285250 & - & - \\
{$[\mathrm{emim}]\left[\mathrm{NO}_{3}\right]+$ Pyrrole } & -835.538317 & 0.000390 & -35.069557 \\
{$[$ emim $]\left[\mathrm{NO}_{3}\right]+$ Indole } & -989.229975 & 0.000390 & -36.117233 \\
{$[$ emim] $]\left[\mathrm{NO}_{3}\right]+$ Methylbenzene } & -896.927704 & 0.000108 & -3.124646 \\
\hline
\end{tabular}

${ }^{\mathrm{a}} 1$ Hartree $=27.211 \mathrm{eV}=627.509 \mathrm{kcal} \cdot \mathrm{mol}^{-1}=2625.753 \mathrm{~kJ} \cdot \mathrm{mol}^{-1}$.

\section{Electron Densities Analysis}

Consistent with the above results, deformation electron density has also been applied to analyze the existing interaction by calculating the electron density distribution. Then, the visualized interactions between those molecules can be obtained and are expressed in Figure 8. A certain degree of $\mathrm{H}^{\cdots} \mathrm{O}$ bonding interaction is in evidence, as seen from the slice of the density map, in which the density of the receiving electron area encircled the $\mathrm{O}$ atom (shown in red), while the betatopic area encircling the $\mathrm{H}$ atom is shown in blue. A certain bonding effect exists between pyrrole/indole and the $\mathrm{O}$ atom in the nitrate anion.

(a)

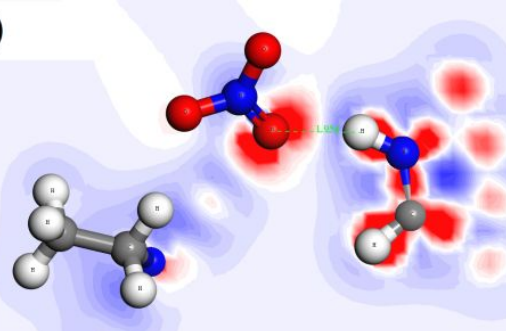

(b)

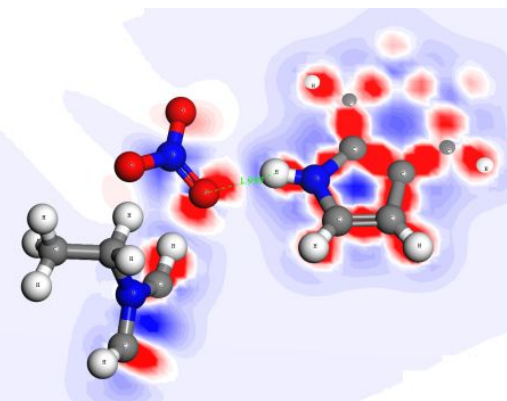


Figure 8. Deformation charge density maps for $[\mathrm{emim}]\left[\mathrm{NO}_{3}\right]+$ pyrrole (a)/indole (b).

Through intermolecular interaction analysis, the conclusion for the extraction process can be ascribed to the existing hydrogen bond between the nitrate anion and the hydrogen atom connected to the heteroatoms presenting the mechanism at the molecular level. The strength of the intermolecular interactions is consistent with the MD simulation results. Also, in accordance with experimental distribution coefficient and selectivity.

\section{Extraction Experimental Validation}

Based on the above results, the multiscale exploration for the extraction process by the adopted [emim $]\left[\mathrm{NO}_{3}\right]$ were investigated. Those results provide a reference for designing the separation process that could help us to illustrate its mechanism. To validate the calculated and simulated results, necessary extraction experiments were performed. Thus, the main factors, such as the mass ratio, extraction temperature, and time were optimized to support the calculation and simulation results.

The influence of the mass ratio of extractants to model oil, extraction temperature, and time was adopted to study by the single-factor experiments. The experimental conditions were optimized, the extraction results are presented in Figure 9, which can confirm the calculated and simulated analysis. The economy of the separation operation was attributed to the dosage of the extractant. Therefore, this factor was studied at room temperature $\left(25^{\circ} \mathrm{C}\right)$ for $30 \mathrm{~min}$ with the mass ratio of [emim] $\left[\mathrm{NO}_{3}\right]$ to oil of $1: 10,1: 5,1: 2$, and $1: 1$, which was experimentally determined to be a reasonable extractant dosage. As shown in Figure 9 (a), the extraction efficiencies for pyrrole and 
indole were all greater than $90 \%$ at the mass ratio of $1: 1$, and its values were all increased with the increase of the $[\mathrm{emim}]\left[\mathrm{NO}_{3}\right]$ dosage. However, the amount of increase hardly changed with the shift in mass ratio from 1:5 to 1:1. Moreover, the pyrrole was slightly larger than the extraction capacity for indole under such conditions. Therefore, 1:5 was adopted to guarantee the economics of the extraction process.

As shown in Figure 9 (b), the extraction temperature was investigated to explain how the temperatures influenced the extraction process. The extraction efficiency was generally exhibiting a decreasing trend when the temperature increased, but the decrease was limited. There was no phase transition during the extraction process that was caused by the properties of $[\mathrm{emim}]\left[\mathrm{NO}_{3}\right]$. The solubility of pyrrole/indole was increased as the temperature increased, which made the extraction efficiency lower. Like the extractant dosage, the extraction efficiency for pyrrole was still slightly larger than the extraction efficiency for indole due to the larger steric hindrance for indole rather than pyrrole. Thus, room temperature can be used as a reasonable temperature.

Finally, the extraction times were investigated from 5 to $60 \mathrm{~min}(10,20,30$, and $60 \mathrm{~min})$. The optimized mass ratio and temperature were adopted to perform the further study. The organicphase compounds, pyrrole and indole, were rapidly moved to the IL phase, especially in the first $10 \mathrm{~min}$. Then, the extraction efficiency curves flattened as the time increased to $60 \mathrm{~min}$. The results are shown in Figure 9 (c). Based on the above analysis, it takes at least 10 min to reach the extraction equilibrium in this work. 
Figure 9. Extraction efficiency of mass ratio, extraction temperature, and time for pyrrole (red, $\mathbf{a})$ and indole (blue, $\bullet$ ).

The optimized factors were achieved by studying the mass ratio, extraction temperature, and time. Excellent results were obtained by the interactions formed between functional groups of [emim $]\left[\mathrm{NO}_{3}\right]$ and pyrrole/indole. Since it was a complicated mixture of the studied systems in this work, the selectivity for the target pyrrole and indole were of particular importance. Therefore, taking as many typical components as possible from some fractions of coal tar as an example, the alkaline (pyridine, quinoline), aromatic (methylbenzene, naphthalene), aliphatic ( $n$-heptane), and neutral compounds (pyrrole, indole, acenaphthene, dibenzofuran, and thiophene) were considered to verify the selectivity of $[\mathrm{emim}]\left[\mathrm{NO}_{3}\right]$. Thus, the above mentioned components were adopted to prepare the complicated mixture, and methylbenzene $/ n$-heptane were used as the solvent to make the solution. All those components were referred to the actual compositions to prepare the solution. 
Therefore, the optimized extraction factors, $25^{\circ} \mathrm{C}$ with mass ratio of $1: 1$ for $10 \mathrm{~min}$, were adopted to test and compare the selectivity for the neutral $N$-compounds, and the results are shown in Figure 10 and listed in Table S6 in the Supporting Information. The studied [emim] $\left[\mathrm{NO}_{3}\right]$ shows increased selectivity and capacity for the investigated neutral pyrrole and indole, but it has a poor capacity for basic $N$-compounds pyridine and quinoline. Furthermore, the simulated neutral compounds (naphthalene, acenaphthene, dibenzofuran, and thiophene) showed much less extraction efficiency during the separation process, which can eliminate low extraction efficiency caused by the complexity of the compositions of the complicated mixtures.

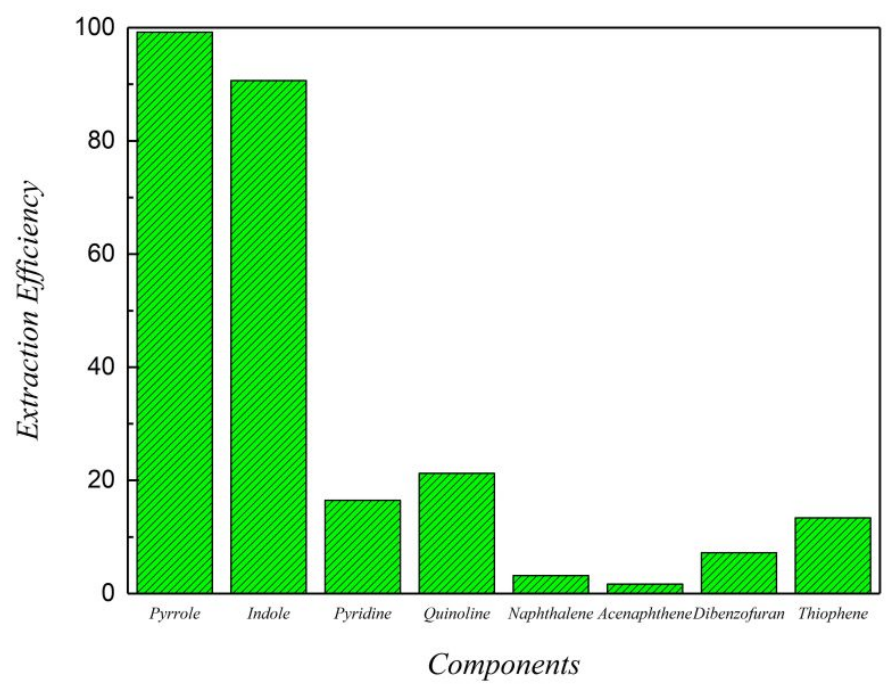

Figure 10. Extraction efficiency for different kinds of components in the mixtures.

\section{Conclusion}

The discovery of extractants for the separation of various value-added compounds with relatively high content is imperative. As a result of obtaining an efficient extractant, $[\mathrm{emim}]\left[\mathrm{NO}_{3}\right]$ was confirmed in a multiscale way to separate neutral $N$-compounds, pyrrole and indole, in this 
work. Therefore, the classical MD simulation and QC calculation were adopted to reveal the extraction mechanism in combination with the LLE tie-line data measurement and extraction validation. First, the $D$ and $S$ values for the two ternary systems were determined, which experimentally confirmed the feasibility in the phase equilibrium perspective. Then, the MD simulation study was adopted to explore the phase equilibrium of the above systems. A good agreement can be shown between the experimental and simulated tie-line data. In addition, the RDF and SDF plots were achieved and explained the microstructure and molecular movement of the investigated systems. Further, to clarify the intermolecular forces between the $[\mathrm{emim}]\left[\mathrm{NO}_{3}\right]$ and $N$-compounds, the charge density analysis combined with the bond length and energy were further verified at the molecular level based on the QC calculation. Through the above analysis, the hydrogen atom was found to be connected to heteroatoms in pyrrole and indole, which formed a hydrogen bond with the nitrate anion in $[\mathrm{emim}]\left[\mathrm{NO}_{3}\right]$. Finally, by combining theoretical and experimental research, the effect of the separation process was evaluated through the extraction experiment, and highly selective separation of neutral pyrrole and indole was discovered. Additionally, the adopted extractant was identified to be the feasible extractant, which can provide a reference for the development of a new extraction process and lay a solid foundation for the extraction of neutral heterocyclic nitrogen compounds from complex systems.

\section{Associated content}

The Supporting Information is available free of charge on the ACS Publications website at 
The detailed procedures of $\mathrm{QC}$ calculation, $\sigma$-profile information, experimental details, and validation for the NRTL model parameters are listed in the Supporting Information.

\title{
Author Information
}

\section{Corresponding Authors}

Jun Gao - College of Chemical and Biological Engineering, Shandong University of Science and Technology, 579 Qianwangang Road, Qingdao 266590, P. R. China; orcid.org/0000-00031145-9565; Email: gao@sdust.edu.cn

Lianzheng Zhang - College of Chemical and Biological Engineering, Shandong University of Science and Technology, 579 Qianwangang Road, Qingdao 266590, P. R. China; orcid.org/00000003-4827-7941; Email: zhanglz@sdust.edu.cn

\begin{abstract}
Authors
Xiaobin Bing - College of Chemical and Biological Engineering, Shandong University of Science and Technology, 579 Qianwangang Road, Qingdao 266590, P. R. China; Email: bingxiaobin@163.com

Ziqi Cui - College of Chemical and Biological Engineering, Shandong University of Science and Technology, 579 Qianwangang Road, Qingdao 266590, P. R. China; Email: czqyyl1120@163.com
\end{abstract}

Juan A. Labarta - Department of Chemical Engineering, University of Alicante, Alicante, 03080, Spain; orcid.org/0000-0002-4870-2031; Email: ja.labarta@ua.es

Dongmei Xu - College of Chemical and Biological Engineering, Shandong University of Science and Technology, 579 Qianwangang Road, Qingdao 266590, P. R. China; orcid.org/00000002-5770-0513; Email: xudongmei.cn@163.com

Shixue Zhou - College of Chemical and Biological Engineering, Shandong University of Science and Technology, 579 Qianwangang Road, Qingdao 266590, P. R. China; Email: zhoushixue66@163.com 
Yinglong Wang - College of Chemical Engineering, Qingdao University of Science and Technology, 53 Zhengzhou Road, Qingdao, 266042, P. R. China; orcid.org/0000-0002-3043-0891;

Email:wangyinglong@qust.edu.cn

Complete contact information is available at: ******

\section{Conflicts of interest}

There are no conflicts of interest to declare.

\section{Acknowledgements}

The authors are grateful to the support of the National Natural Science Foundation of China (No.

21908131), the Natural Science Foundation of Shandong Province (ZR2019BB066), and the Shenzhen Supercomputer Center.

\section{References}

1. Girgis, M. J.; Gates, B. C., Reactivities, reaction networks, and kinetics in high-pressure catalytic hydroprocessing. Ind. Eng. Chem. Res. 1991, 30 (9), 2021-2058, DOI: 10.1021/ie00057a001.

2. Li, N.; Ma, X.; Zha, Q.; Song, C., Analysis and Comparison of Nitrogen Compounds in Different Liquid Hydrocarbon Streams Derived from Petroleum and Coal. Energy Fuels 2010, 24 (10), 5539-5547, DOI: 10.1021/ef1007598.

3. Revellin, N.; Dulot, H.; López-García, C.; Baco, F.; Jose, J., Specific Nitrogen Boiling Point Profiles of Vacuum Gasoils. Energy Fuels 2005, 19 (6), 2438-2444, DOI: 10.1021/ef050127f.

4. Huang, C.; Shi, X.; Wang, C.; Guo, L.; Dong, M.; Hu, G.; Lin, J.; Ding, T.; Guo, Z., Boosted selectivity and enhanced capacity of $\mathrm{As}(\mathrm{V})$ removal from polluted water by triethylenetetramine activated lignin-based adsorbents. Int. J. Biol. Macromol. 2019, 140, 1167-1174, DOI: 10.1016/j.ijbiomac.2019.08.230.

5. Zhang, M.; Meng, J.; Liu, Q.; Gu, S.; Zhao, L.; Dong, M.; Zhang, J.; Hou, H.; Guo, Z., Corn stover-derived biochar for efficient adsorption of oxytetracycline from wastewater. J. Mater. Res. 2019, 34 (17), 3050-3060, DOI: 10.1557/jmr.2019.198.

6. Shi, X.; Wang, C.; Ma, Y.; Liu, H.; Wu, S.; Shao, Q.; He, Z.; Guo, L.; Ding, T.; Guo, Z., Template-free microwave-assisted synthesis of $\mathrm{FeTi}$ coordination complex yolk-shell 
microspheres for superior catalytic removal of arsenic and chemical degradation of methylene blue from polluted water. Powder Technol. 2019, 356, 726-734, DOI: 10.1016/j.powtec.2019.09.002. 7. Zhao, J.; Shao, Q.; Ge, S.; Zhang, J.; Lin, J.; Cao, D.; Wu, S.; Dong, M.; Guo, Z., Advances in Template Prepared Nano-oxides and Their Applications: Polluted Water Treatment, Energy, Sensing and Biomedical Drug Delivery. Chem. Rec. 2020, 20, 1-21, DOI: 10.1002/tcr.201900093. 8. Zhang, L.; Zhang, M.; Gao, J.; Xu, D.; Zhou, S.; Wang, Y., Efficient Extraction of Neutral Heterocyclic Nitrogen Compounds from Coal Tar via Ionic Liquids and Its Mechanism Analysis. Energy Fuels 2018, 32 (9), 9358-9370, DOI: 10.1021/acs.energyfuels.8b02297.

9. Zhang, L.; Xu, D.; Gao, J.; Zhou, S.; Zhao, L.; Zhang, Z., Extraction and mechanism for the separation of neutral N-compounds from coal tar by ionic liquids. Fuel 2017, 194, 27-35, DOI: 10.1016/j.fuel.2016.12.095.

10. Shui, H.; Zhang, D.; Zhang, C., Separation and Refined of Coal Tar. Chemical Industry Press: Beijing, 2007; pp 1-14.

11. Yanagiuchi, M.; Kato, T.; Ueda, T.; Matubara, K.; Arai, K.; Inomata, H.; Saito, S., Separation and purification of indole from coal tar by supercritical fluid extraction. J. Chem. Eng. Jpn. 1993, 26 (2), 153-158, DOI: 10.1252/jcej.26.153.

12. Merdrignac, I.; Behar, F.; Albrecht, P.; Briot, P.; Vandenbroucke, M., Quantitative extraction of nitrogen compounds in oils: atomic balance and molecular composition. Energy Fuels 1998, 12 (6), 1342-1355, DOI: 10.1021/ef980103r.

13. Jin Kim, S.; Jin Chun, Y., Separation of nitrogen heterocyclic compounds from model coal tar fraction by solvent extraction. Sep. Sci. Technol. 2005, 40 (10), 2095-2109, DOI: 10.1081/SS200068488.

14. Qi, J.; Yan, Y.; Su, Y.; Qu, F.; Dai, Y., Extraction of nitrogen compounds from catalytically cracked diesel oil with a volatile carboxylic acid based on reversible chemical complexation. Energy Fuels 1998, 12 (4), 788-791, DOI: 10.1021/ef9800031.

15. Dong, K.; Liu, X.; Dong, H.; Zhang, X.; Zhang, S., Multiscale Studies on Ionic Liquids. Chem. Rev. 2017, 117 (10), 6636-6695, DOI: 10.1021/acs.chemrev.6b00776.

16. Clarke, C. J.; Tu, W. C.; Levers, O.; Brohl, A.; Hallett, J. P., Green and Sustainable Solvents in Chemical Processes. Chem. Rev. 2018, 118 (2), 747-800, DOI: 10.1021/acs.chemrev.7b00571. 17. Pena-Pereira, F.; Namiesnik, J., Ionic liquids and deep eutectic mixtures: sustainable solvents for extraction processes. ChemSusChem 2014, 7 (7), 1784-800, DOI: 10.1002/cssc.201301192.

18. Ali, M. C.; Yang, Q.; Fine, A. A.; Jin, W.; Zhang, Z.; Xing, H.; Ren, Q., Efficient removal of both basic and non-basic nitrogen compounds from fuels by deep eutectic solvents. Green Chem. 2016, 18 (1), 157-164, DOI: 10.1039/C5GC01823D.

19. Xu, D.; Zhang, M.; Gao, J.; Zhang, L.; Zhou, S.; Wang, Y., Separation of heterocyclic nitrogen compounds from coal tar fractions via ionic liquids: COSMO-SAC screening and experimental study. Chem. Eng. Commun. 2019, 206 (9), 1199-1217, DOI: 10.1080/00986445.2018.1552855. 20. Gai, H.; Qiao, L.; Zhong, C.; Zhang, X.; Xiao, M.; Song, H., Designing Ionic Liquids with Dual Lewis Basic Sites to Efficiently Separate Phenolic Compounds from Low-Temperature Coal Tar. ACS Sustainable Chem. Eng. 2018, 6 (8), 10841-10850, DOI: 10.1021/acssuschemeng.8b02119. 
21. Su, X.; Song, J.; Yang, J.; Xu, X., Extractive denitrification of coal tar diesel fraction using phosphate-based alkylimidazolium ionic liquids. Huagong Jinzhan 2016, 04 (04), 1081-1086, DOI: 10.16085/j.issn.1000-6613.2016.04.018.

22. Jiao, T.; Zhuang, X.; He, H.; Zhao, L.; Li, C.; Chen, H.; Zhang, S., An ionic liquid extraction process for the separation of indole from wash oil. Green Chem. 2015, 17 (7), 3783-3790, DOI: 10.1039/C5GC00081E.

23. Ventura, S. P. M.; FA, E. S.; Quental, M. V.; Mondal, D.; Freire, M. G.; Coutinho, J. A. P., Ionic-Liquid-Mediated Extraction and Separation Processes for Bioactive Compounds: Past, Present, and Future Trends. Chem. Rev. 2017, 117 (10), 6984-7052, DOI: 10.1021/acs.chemrev.6b00550.

24. Gao, J.; Xu, D.; Cha, X.; Cui, Z.; Zhang, L.; Wang, Y., Multiscale modeling and liquid-liquid equilibria insights for the extraction of heterocyclic nitrogen compounds from coal tar via [emim][TOS] as extractant. J. Mol. Liq. 2019, 277, 825-832, DOI: 10.1016/j.molliq.2019.01.021. 25. Abro, R.; Abro, M.; Gao, S.; Bhutto, A. W.; Ali, Z. M.; Shah, A.; Chen, X.; Yu, G., Extractive denitrogenation of fuel oils using ionic liquids: a review. RSC Adv. 2016, 6 (96), 93932-93946, DOI: 10.1039/C6RA09370A.

26. Fan, Y.; Cai, D.; Zhang, S.; Wang, H.; Guo, K.; Zhang, L.; Yang, L., Effective removal of nitrogen compounds from model diesel fuel by easy-to-prepare ionic liquids. Sep. Purif. Technol. 2019, 222, 92-98, DOI: 10.1016/j.seppur.2019.04.026.

27. Hansmeier, A. R.; Meindersma, G. W.; de Haan, A. B., Desulfurization and denitrogenation of gasoline and diesel fuels by means of ionic liquids. Green Chem. 2011, 13 (7), 1907-1913, DOI: 10.1039/C1GC15196G.

28. Alonso, L.; Arce, A.; Francisco, M. a.; Soto, A., Extraction ability of nitrogen-containing compounds involved in the desulfurization of fuels by using ionic liquids. J. Chem. Eng. Data 2010, 55 (9), 3262-3267, DOI: 10.1021/je100075m.

29. Zhang, L.; Xu, D.; Gao, J.; Zhang, M.; Xia, Z.; Ma, Y.; Zhou, S., Separation of the mixture pyridine + methylbenzene via several acidic ionic liquids: Phase equilibrium measurement and correlation. Fluid Phase Equilib. 2017, 440, 103-110, DOI: 10.1016/j.fluid.2017.03.009.

30. Su, B.-M.; Zhang, S.; Zhang, Z. C., Structural elucidation of thiophene interaction with ionic liquids by multinuclear NMR spectroscopy. J. Phys. Chem. B 2004, 108 (50), 19510-19517, DOI: 10.1021/jp0490271.

31. Hu, Q.; Zhou, N.; Gong, K.; Liu, H.; Liu, Q.; Sun, D.; Wang, Q.; Shao, Q.; Liu, H.; Qiu, B.; Guo, Z., Intracellular Polymer Substances Induced Conductive Polyaniline for Improved Methane Production from Anaerobic Wastewater Treatment. ACS Sustainable Chem. Eng. 2019, 7 (6), 5912-5920, DOI: 10.1021/acssuschemeng.8b05847.

32. Zhang, S.; Zhang, Q.; Zhang, Z. C., Extractive Desulfurization and Denitrogenation of Fuels Using Ionic Liquids. Ind. Eng. Chem. Res. 2004, 43 (2), 614-622, DOI: 10.1021/ie030561+. 33. Holbrey, J. D.; Reichert, W. M.; Nieuwenhuyzen, M.; Sheppard, O.; Hardacre, C.; Rogers, R. D., Liquid clathrate formation in ionic liquid-aromatic mixtures. Chem. Commun. 2003, 4 (4), 476-477, DOI: 10.1039/B212726A.

34. Wang, H.; Xie, C.; Yu, S.; Liu, F., Denitrification of simulated oil by extraction with $\mathrm{H}_{2} \mathrm{PO}_{4}{ }^{-}$ 
based ionic liquids. Chem. Eng. J. 2014, 237, 286-290, DOI: 10.1016/j.cej.2013.10.049.

35. Abraham, M. H.; Dearden, J. C.; Bresnen, G. M., Hydrogen bonding, steric effects and thermodynamics of partitioning. J. Phys. Org. Chem. 2006, 19 (4), 242-248, DOI: 10.1002/poc.1027.

36. Mali, K. S.; Dutt, G. B.; Mukherjee, T., Do organic solutes experience specific interactions with ionic liquids? J. Chem. Phys. 2005, 123 (17), 174504, DOI: 10.1063/1.2102847.

37. Zhao, Y.; Deng, S.; Liu, H.; Zhang, J.; Guo, Z.; Hou, H., First-principle investigation of pressure and temperature influence on structural, mechanical and thermodynamic properties of $\mathrm{Ti}_{3} \mathrm{AC}_{2} \quad(\mathrm{~A}=\mathrm{Al}$ and $\mathrm{Si})$. Comput. Mater. Sci. 2018, 154, 365-370, DOI: 10.1016/j.commatsci.2018.07.007.

38. Sun, Z.; Zhang, L.; Dang, F.; Liu, Y.; Fei, Z.; Shao, Q.; Lin, H.; Guo, J.; Xiang, L.; Yerra, N.; Guo, Z., Experimental and simulation-based understanding of morphology controlled barium titanate nanoparticles under co-adsorption of surfactants. CrystEngComm 2017, 19 (24), 32883298, DOI: 10.1039/C7CE00279C.

39. Zhao, J.; Wu, L.; Zhan, C.; Shao, Q.; Guo, Z.; Zhang, L., Overview of polymer nanocomposites: Computer simulation understanding of physical properties. Polymer 2017, 133, 272-287, DOI: 10.1016/j.polymer.2017.10.035.

40. Ramalingam, A., Interaction energy of pyrrole and pyridine with 1-ethyl-3methylimidazolium ethyl sulphate. J. Mol. Liq. 2017, 231, 56-63, DOI: 10.1016/j.molliq.2017.01.082.

41. Bhoi, S.; Mohanty, K.; Banerjee, T., Quantum chemical insights and continuum solvation predictions on the dissolution of bituminous and anthracite coal in Ionic Liquid. J. Mol. Liq. 2016, 221, 919-929, DOI: 10.1016/j.molliq.2016.06.042.

42. Verdía, P.; González, E. J.; Moreno, D.; Palomar, J.; Tojo, E., Deepening of the Role of Cation Substituents on the Extractive Ability of Pyridinium Ionic Liquids of N-Compounds from Fuels. ACS Sustainable Chem. Eng. 2017, 5 (2), 2015-2025, DOI: 10.1021/acssuschemeng.6b02922.

43. Naik, P. K.; Mohan, M.; Banerjee, T.; Paul, S.; Goud, V. V., Molecular Dynamic Simulations for the Extraction of Quinoline from Heptane in the Presence of a Low-Cost Phosphonium-Based Deep Eutectic Solvent. J. Phys. Chem. B 2018, 122 (14), 4006-4015, DOI: 10.1021/acs.jpcb.7b10914.

44. Welton, T., Solvents and sustainable chemistry. Proceedings of the Royal Society A: Mathematical, Physical and Engineering Sciences 2015, 471 (2183), 20150502, DOI: 10.1098/rspa.2015.0502.

45. Abraham, M. J.; Murtola, T.; Schulz, R.; Páll, S.; Smith, J. C.; Hess, B.; Lindahl, E., GROMACS: High performance molecular simulations through multi-level parallelism from laptops to supercomputers. SoftwareX 2015, 1-2, 19-25, DOI: 10.1016/j.softx.2015.06.001.

46. Wang, J.; Wolf, R. M.; Caldwell, J. W.; Kollman, P. A.; Case, D. A., Development and testing of a general amber force field. J. Comput. Chem. 2004, 25 (9), 1157-1174, DOI: 10.1002/jcc.20035. 47. Wang, J.; Wang, W.; Kollman, P. A.; Case, D. A., Automatic atom type and bond type perception in molecular mechanical calculations. J. Mol. Graphics Modell. 2006, 25 (2), 247-260, DOI: 10.1016/j.jmgm.2005.12.005. 
48. Hess, B.; Bekker, H.; Berendsen, H. J. C.; Fraaije, J. G. E. M., LINCS: A linear constraint solver for molecular simulations. Journal of Computational Chemistry 1997, 18 (12), 1463-1472, DOI: 10.1002/(SICI)1096-987X(199709)18:12<1463::AID-JCC4>3.0.CO;2-H.

49. Bussi, G.; Donadio, D.; Parrinello, M., Canonical sampling through velocity rescaling. $J$. Chem. Phys. 2007, 126 (1), 014101, DOI: 10.1063/1.2408420.

50. Taha, M.; Lee, M.-J., TES buffer-induced phase separation of aqueous solutions of several water-miscible organic solvents at $298.15 \mathrm{~K}$ : Phase diagrams and molecular dynamic simulations. J. Chem. Phys. 2013, 138 (24), 244501, DOI: 10.1063/1.4809995.

51. Martinez, L.; Andrade, R.; Birgin, E. G.; Martinez, J. M., PACKMOL: a package for building initial configurations for molecular dynamics simulations. J. Comput. Chem. 2009, 30 (13), $2157-$ 2164, DOI: $10.1002 /$ jcc. 21224.

52. Humphrey, W.; Dalke, A.; Schulten, K., VMD: Visual molecular dynamics. J. Mol. Graphics 1996, 14 (1), 33-38, DOI: 10.1016/0263-7855(96)00018-5.

53. Zhou, Y.; Xu, D.; Zhang, L.; Ma, Y.; Ma, X.; Gao, J.; Wang, Y., Separation of thioglycolic acid from its aqueous solution by ionic liquids: Ionic liquids selection by the COSMO-SAC model and liquid-liquid phase equilibrium. J. Chem. Thermodyn. 2018, 118, 263-273, DOI: 10.1016/j.jct.2017.12.007.

54. Wang, P.; Xu, D.; Yan, P.; Gao, J.; Zhang, L.; Wang, Y., Separation of azeotrope (ethanol and ethyl methyl carbonate) by different imidazolium-based ionic liquids: Ionic liquids interaction analysis and phase equilibrium measurements. J. Mol. Liq. 2018, 261, 89-95, DOI: 10.1016/j.molliq.2018.04.001.

55. Karpińska, M.; Wlazło, M.; Domańska, U., Investigation on the ethylbenzene/styrene separation efficiency with ionic liquids in liquid-liquid extraction. Chem. Eng. Res. Des. 2017, 128, 214-220, DOI: 10.1016/j.cherd.2017.10.016.

56. Larriba, M.; Navarro, P.; Delgado-Mellado, N.; Stanisci, V.; García, J.; Rodríguez, F., Separation of aromatics from $\mathrm{n}$-alkanes using tricyanomethanide-based ionic liquids: Liquidliquid extraction, vapor-liquid separation, and thermophysical characterization. J. Mol. Liq. 2016, 223, 880-889, DOI: 10.1016/j.molliq.2016.09.017.

57. Dai, F.; Xin, K.; Song, Y.; Shi, M.; Zhang, H.; Li, Q., Liquid-liquid equilibria for the extraction of phenols from alkane using ethylene glycol. Fluid Phase Equilib. 2016, 419, 50-56, DOI: 10.1016/j.fluid.2016.03.003.

58. Wang, Y.; Liu, X.; Kraslawski, A.; Gao, J.; Cui, P., A novel process design for $\mathrm{CO}_{2}$ capture and $\mathrm{H}_{2} \mathrm{~S}$ removal from the syngas using ionic liquid. J. Cleaner Prod. 2019, 213, 480-490, DOI: 10.1016/j.jclepro.2018.12.180.

59. Wang, Y.; Bu, G.; Geng, X.; Zhu, Z.; Cui, P.; Liao, Z., Design optimization and operating pressure effects in the separation of acetonitrile/methanol/water mixture by ternary extractive distillation. J. Cleaner Prod. 2019, 218, 212-224, DOI: 10.1016/j.jclepro.2019.01.324.

60. Bai, W.; Dai, Y.; Pan, X.; Zhu, Z.; Wang, Y.; Gao, J., Liquid-liquid equilibria for azeotropic mixture of methyl tert-butyl ether and methanol with ionic liquids at different temperatures. $J$. Chem. Thermodyn. 2019, 132, 76-82, DOI: 10.1016/j.jct.2018.12.029.

61. Wang, Y.; Bu, G.; Bai, W.; Cui, P.; Zhu, Z.; Zhang, F., Liquid-Liquid Equilibrium Data for 
the Systems n-Propyl Acetate or Isopropyl Acetate + n-Propanol or Isopropyl Alcohol + IL at 298.15 and 318.15 K and Atmospheric Pressure. J. Chem. Eng. Data 2018, 63 (12), 4761-4766, DOI: $10.1021 /$ acs.jced.8b00776.

62. Marcilla, A.; Reyes-Labarta, J. A.; Olaya, M. M., Should we trust all the published LLE correlation parameters in phase equilibria? Necessity of their assessment prior to publication. Fluid Phase Equilib. 2017, 433, 243-252, DOI: 10.1016/j.fluid.2016.11.009.

63. Marcilla, A.; Olaya, M. M.; Serrano, M. D.; Reyes-Labarta, J. A., Aspects To Be Considered for the Development of a Correlation Algorithm for Condensed Phase Equilibrium Data of Ternary Systems. Ind. Eng. Chem. Res. 2010, 49 (20), 10100-10110, DOI: 10.1021/ie1010383.

64. Reyes-Labarta, J. A.; Olaya, M. M.; Velasco, R.; Serrano, M. D.; Marcilla, A., Correlation of the liquid-liquid equilibrium data for specific ternary systems with one or two partially miscible binary subsystems. Fluid Phase Equilib. 2009, 278 (1-2), 9-14, DOI: 10.1016/j.fluid.2008.12.002. 65. Rodriguez-Escontrela, I.; Arce, A.; Soto, A.; Marcilla, A.; Olaya, M. M.; Reyes-Labarta, J. A., Correlation of three-liquid-phase equilibria involving ionic liquids. Phys. Chem. Chem. Phys. 2016, 18 (31), 21610-21617, DOI: 10.1039/C6CP03467E.

66. Wang, P.; Yan, P.; Reyes-Labarta, J. A.; Gao, J.; Xu, D.; Zhang, L.; Wang, Y., Liquid-liquid measurement and correlation for separation of azeotrope (dimethyl carbonate and ethanol) with different imidazolium-based ionic liquids. Fluid Phase Equilib. 2019, 485, 183-189, DOI: 10.1016/j.fluid.2018.12.034.

67. Brehm, M.; Kirchner, B., TRAVIS - a free analyzer and visualizer for Monte Carlo and molecular dynamics trajectories. J. Chem. Inf. Model 2011, 51 (8), 2007-2023, DOI: doi.org/10.1021/ci200217w. 


\section{For Table of Contents Use Only}

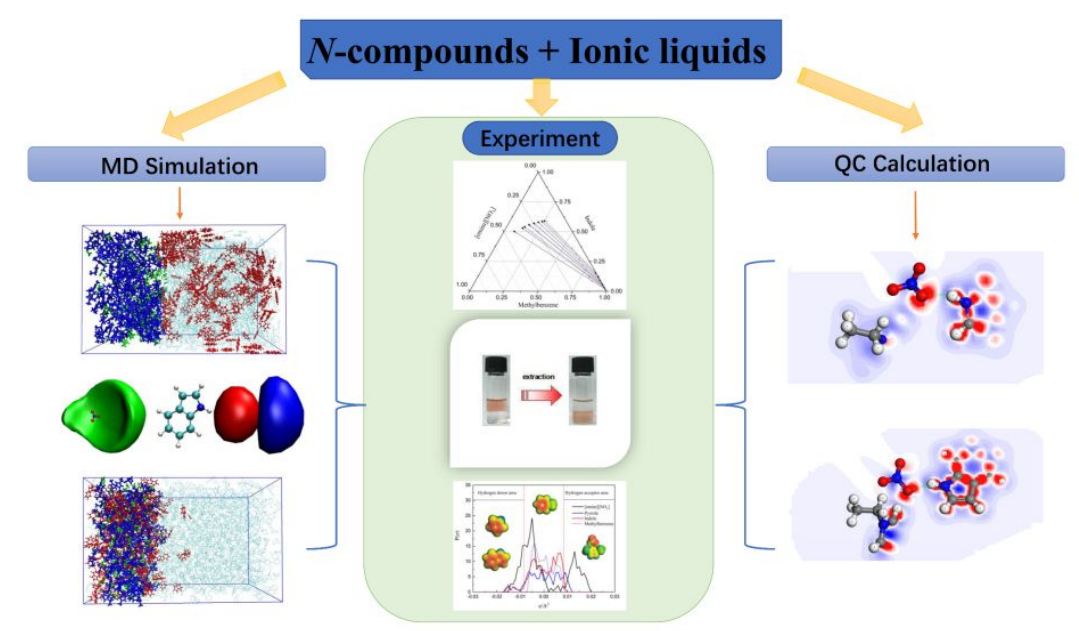

\section{Synopsis}

Theoretical and experimental research for the extraction of complex systems containing neutral heterocyclic $N$-compounds by $[\mathrm{emim}]\left[\mathrm{NO}_{3}\right]$. 